\title{
Triazole-Extended Anthracenes as Optical Force Probes
}

\author{
Christoph Baumann ${ }^{\mathrm{a}, \mathrm{b}}$ (1) \\ Robert Göstl *a (i) \\ a DWI - Leibniz Institute for Interactive Materials, Forckenbeckstr. \\ 50, 52056 Aachen, Germany \\ goestl@dwi.rwth-aachen.de \\ b Institute of Technical and Macromolecular Chemistry, RWTH \\ Aachen University, Worringerweg 1, 52074 Aachen, Germany \\ Published as part of the Cluster \\ Mechanochemistry
}

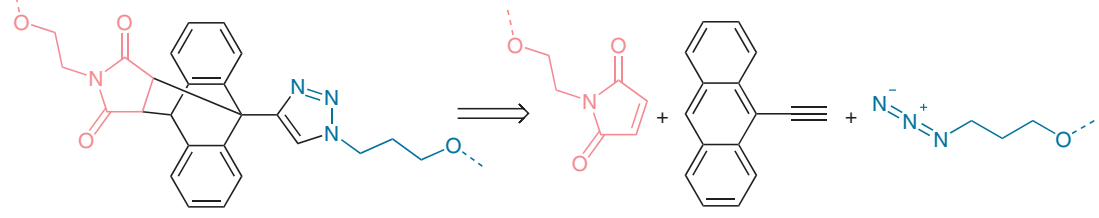

triazole-extended anthracene optical force probes by double "click" reaction
Received: 11.08 .2021

Accepted after revision: 16.09.2021

Published online: 14.10 .2021

DOI: 10.1055/s-0040-1720924; Art ID: st-2021-r0289-c

\section{License terms: CC)}

(c) 2021. The Author(s). This is an open access article published by Thieme under the terms of the Creative Commons Attribution-NonDerivative-NonCommercial-License, permitting copying and reproduction so long as the original work is given appropriate credit. Contents may not be used for commercial purposes or adapted, remixed, transformed or built upon. (https://creativecommons.org/licenses/by-nc-nd/4.0/)

Abstract Optical force probes (OFPs) are force-responsive molecules that report on mechanically induced transformations by the alteration of their optical properties. Yet, their modular design and incorporation into polymer architectures at desired positions is challenging. Here we report triazole-extended anthracene OFPs that combine two modular 'click' reactions in their synthesis potentially allowing their incorporation at desirable positions in complex polymer materials. Importantly, these retain the excellent optical properties of their parent 9 - $\pi$-extended anthracene OFP counterparts.

Key words mechanochemistry, fluorescence, polymers, cycloaddition, chromophores

The prerequisite for the comprehensive understanding of the mechanical properties of polymers is the correlation of their macroscopic mechanical properties with those of their molecular constituents. Optical force probes (OFPs) are force-responsive molecules (mechanophores) ${ }^{1,2}$ that, when embedded into a polymer material, report mechanically induced transformations by the alteration of their optical properties. ${ }^{3-5}$ Thereby, they are rendered promising

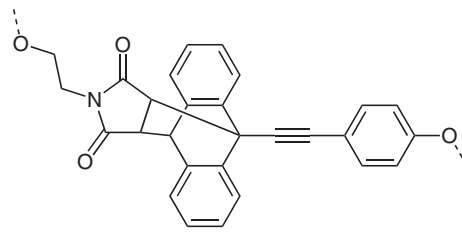

previous $\pi$-extended anthracene OFP candidates for this endeavor. Several OFPs have been reported to the literature including, but not limited to spiropyran, ${ }^{6,7}$ dioxetane, ${ }^{8,9}$ persistent delocalized radicals, ${ }^{10-12}$ or aggregachromic dyes. ${ }^{13-15}$ Diels-Alder adducts of anthracene and maleimide, ${ }^{16-18}$ particularly those that bear extended $\pi$-electron systems (Figure 1 ), ${ }^{19-21}$ have been used to display forces with high sensitivity, ${ }^{19,20,22,23}$ high spatial resolution, ${ }^{21,24-26}$ and for the quantification ${ }^{27}$ of bond-scission events. $^{21,25}$ Yet, the eventual success of OFPs will be determined not only by their properties and insights that can be obtained but also by their straightforward synthetic access and their ability to be incorporated within complex, nonuniform materials at desirable positions. Therefore, simplifications in both OFP synthesis and their conjugation to the polymer architecture are desirable.

Here we report a new, synthetically facile approach to extend anthracene-maleimide Diels-Alder adduct OFPs with triazoles using the azide-alkyne Huisgen 1,3-dipolar cycloaddition (Figure 1). By this, we equip these OFPs with an additional site for 'click' conjugation to the polymer architecture while maintaining a brightness comparable to the established $\pi$-extended anthracene fluorophores.

OFP synthesis was conducted with the reported ${ }^{19-21}$ terminal alkyne Diels-Alder adduct 1 (Scheme 1). This was subjected to a reductive azide-alkyne cycloaddition ${ }^{28}$ using sodium L-ascorbate and $\mathrm{CuSO}_{4}$ together with 3-azido-1propanol to form the OFP diol 2 with quantitative conversion and $70 \%$ yield $^{29}$ due to losses during workup (Figures

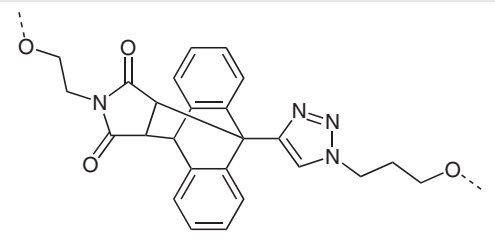

triazole-extended anthracene OFP in this work

Figure 1 Comparison of previously investigated $\pi$-extended anthracene OFP and the triazole-extended anthracene OFP of this work. Dashed bonds signify the connection to the polymer. 
<smiles>C#CC12c3ccccc3C(c3ccccc31)C1C(=O)N(CCO)C(=O)C12</smiles>

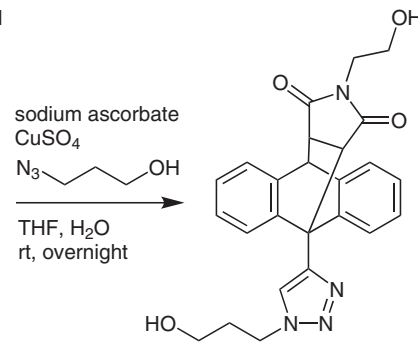

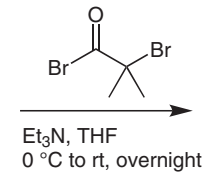

2

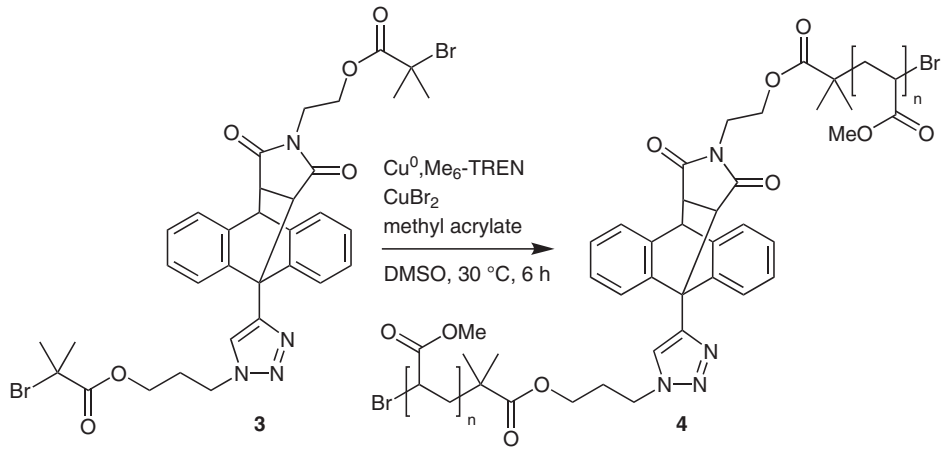<smiles>COCCCn1cc(-c2c3ccccc3cc3ccccc23)nn1</smiles>

Scheme 1 Synthesis of triazole-extended anthracene OFP $\mathbf{3}$, its polymer $\mathbf{4}$, and the subsequent mechanochemical activation of 4

S1-S3). Importantly, no purification besides collection of the product precipitate by filtration and washing was necessary. OFP diol 2 was then esterified using $\alpha$-bromoisobutyryl bromide yielding the bifunctional initiator $\mathbf{3}$ for controlled radical polymerization (CRP, Figures S4-S6). ${ }^{19-21}$ To assess the OFP performance, initiator $\mathbf{3}$ was incorporated into the center of linear poly (methyl acrylate) (PMA) chains via $\mathrm{Cu}^{0}$-catalyzed $\mathrm{CRP}^{19-21}$ whereupon polymer $\mathbf{4}\left(M_{n}=60.9\right.$ $\mathrm{kDa}, \bigoplus_{M}=1.17$, Figure $2 \mathrm{a}$ ) was obtained. It should be noted here that this reaction order was chosen to fully characterize the OFP in a defined polymer chain. In principle, both the Huisgen and Diels-Alder reactions can be performed using polymer-terminated azides or maleimides allowing access to complex conjugation sequences.

To assess the mechanochemical performance of the OFP, a solution of polymer $\mathbf{4}$ was then subjected to pulsed ( $1 \mathrm{~s}$ 'on', $2 \mathrm{~s}$ 'off') ultrasonication using an immersion probe sonicator $(20 \mathrm{kHz})^{30}$ for low conversions to allow the initial slope approximation for rate constant determination. The proceeding mechanochemical reaction was followed by gel permeation chromatography (GPC) via refractive index (RI) detector and by UV/Vis absorption spectroscopy. Over the course of the sonication, a decrease of the peak molar mass of 4 (ca. $60 \mathrm{kDa}$ ) was observed and chain fragments at ap-
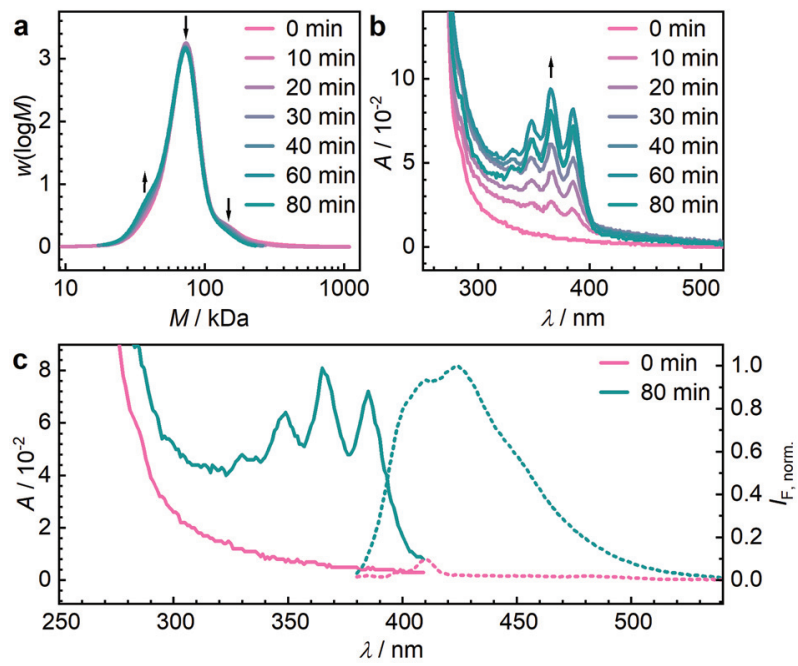

Figure 2 Monitoring of the sonochemical scission of 4. (a) GPC RI elugrams showing the molar mass distribution over sonication time. (b) UV/Vis spectroscopy showing the increasing absorption over sonication time. (c) Comparison of absorption and normalized fluorescence $\left(\lambda_{\text {exc }}=\right.$ $365 \mathrm{~nm}$ ) before and after sonication. 


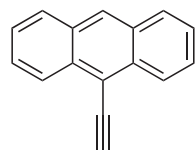

5

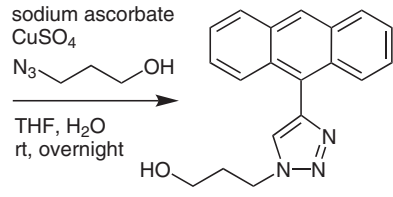

6
Scheme 2 Synthesis of control compound 6 by Huisgen cycloaddition

proximately half the initial peak molar mass emerged (Figure 2a). This hinted towards the expected force-induced chain scission in the central region of the polymer chain.

The accompanying UV/Vis absorption measurements additionally revealed that a chromophore was generated during this process transitioning from a mostly transparent 4 only absorbing at $\lambda<300 \mathrm{~nm}$ to a species bearing the vibronic signature of anthracene between $\lambda=325-425 \mathrm{~nm}$ (Figure 2b). Fluorescence spectroscopy was performed before and after the sonication and revealed a transition from an expectedly nonfluorescent $\mathbf{4}$ to a fluorescent species with an emission maximum at $\lambda_{\mathrm{em}}=424 \mathrm{~nm}$ (Figure 2c).

To verify the mechanochemical origin of the fluorogenic reaction, to determine the molar absorptivity $\varepsilon$, and to obtain the fluorescence quantum yield $\Phi$ of the emitter, control compound 6 resembling the activated mechanofluorophore was synthesized from 9-ethynylanthracene (5, Scheme 2, Figures S7-S9). The absorption spectra of $\mathbf{6}$ in MeCN were recorded with concentrations between 5-70 $\mu \mathrm{mol} \mathrm{L}^{-1}$ and the measured absorbance at $\lambda=365 \mathrm{~nm}$ was plotted against the dye concentration (Figure $3 a$ ). The linear fit with a fixed intercept at 0 resulted in $\varepsilon_{6}=8148 \mathrm{~L} \mathrm{~mol}^{-1}$ $\mathrm{cm}^{-1}$ as indicated by the slope of the regression curve. A comparison with the spectral data derived from the sonication experiments (Figure $3 \mathrm{~b}$ ) indicated a strong agreement between the two fluorophores both in absorption and emission. This corroborated a successful and reasonably selective force-induced cycloelimination reaction. $\Phi_{6}$ was determined to 0.77 ( $\mathrm{MeCN}, \lambda_{\text {exc }}=365 \mathrm{~nm}$ ) using an Ulbricht sphere. This value significantly exceeded the fluorescence quantum yield of regular anthracene with $\Phi=0.27\left(\mathrm{C}_{6} \mathrm{H}_{6}\right.$, $\left.\lambda_{\text {exc }}=365 \mathrm{~nm}\right){ }^{31} \Phi_{6}$ was comparable to 9 - $\pi$-extended anthracene which we have reported before ( $c f$. Figure 1) where $\Phi=0.72\left(\mathrm{MeCN}, \lambda_{\text {exc }}=372 \mathrm{~nm}\right) \cdot{ }^{19}$ A comparable anthracene-triazole structure bearing a $\mathrm{C}_{8} \mathrm{H}_{17}$ chain reported in the literature also showed an increased $\Phi=0.45$ $(\mathrm{MeCN})^{32}$ indicating that extensions with triazoles could be a generally viable approach to achieve high fluorophore brightness in anthracene-based OFPs.

The apparent sonochemical scission rate constants $k$ were determined from GPC measurements (Figure 2a) over the course of sonication using the Nalepa method ${ }^{33-35}$ and via UV/Vis spectroscopy (Figure 2b) using $\varepsilon_{6} \cdot{ }^{19}$ Both approaches led to comparable values, hinting towards a pre-
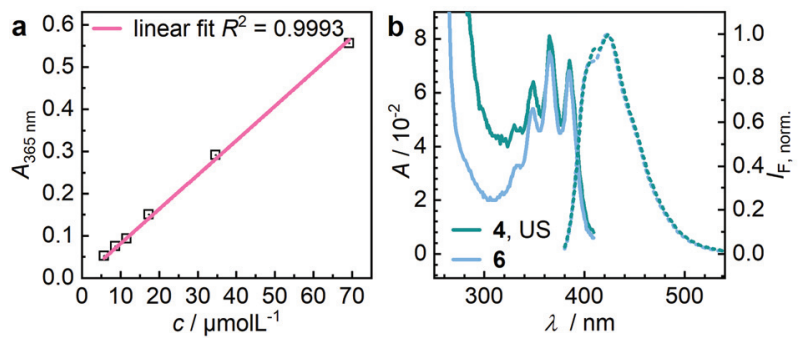

Figure 3 Optical properties of control dye 6 . (a) Determination of the molar absorptivity $\varepsilon_{6}$ and (b) UV/Vis absorption and normalized fluorescence spectra of $\mathbf{4}$ after 80 min sonication and $\mathbf{6}\left(\lambda_{\text {exc }}=365 \mathrm{~nm}, c_{6}=8.7\right.$ $\mu \mathrm{mol} \mathrm{L}{ }^{-1}$, MeCN).

ferred chain scission at the anthracene-maleimide OFP. Values obtained via GPC were slightly higher due to the contribution of nonspecific chain scission. The apparent scission rate constants were calculated to $k_{4, \mathrm{GPC}}=2.13 \cdot 10^{-3} \mathrm{~min}^{-1}$ and $k_{4, \mathrm{UV} / \mathrm{Vis}}=1.27 \cdot 10^{-3} \mathrm{~min}^{-1}$ and were comparable to those measured for other $9-\pi$-extended anthracene OFPs. ${ }^{19-21} \mathrm{~A}$ notable contribution of the cycloelimination of the triazole moiety was not observed. ${ }^{36,37}$

In conclusion, we presented a new mechanofluorophore design based on a combination of the established $9-\pi$-extended anthracene-maleimide Diels-Alder adducts and the 1,4-triazole moiety. The sonochemical bond scission in solution was observed by GPC, UV/Vis, and fluorescence spectroscopy. Both absorption and emission were only slightly bathochromically shifted compared to nonfunctionalized anthracene. Therefore, triazole extension in 9positition of the anthracene led to little conjugation with the chromophore. However, the fluorescence quantum yield was significantly increased maintaining the brightness on a comparable level to previously reported $9-\pi$-extended anthracenes. ${ }^{19-21}$ The combination of two modular 'click' reactions potentially allows various reaction pathways to incorporate these OFPs at desirable positions in complex polymer materials and therefore expands the strategic toolbox for polymer mechanochemistry.

\section{Conflict of Interest}

The authors declare no conflict of interest.

\section{Funding Information}

C.B. and R.G. are grateful for support by a Freigeist-Fellowship of the Volkswagen Foundation (92888). Parts of the analytical investigations were performed at the Center for Chemical Polymer Technology CPT, which was supported by the European Commission and the federal state of North Rhine-Westphalia (300088302). Financial support is acknowledged from the European Commission (EUSMI, 731019). 


\section{Supporting Information}

Supporting information for this article is available online at https://doi.org/10.1055/s-0040-1720924.

\section{Primary Data}

Primary data for this article are available online at https://zenodo.org/record/5175871 and can be cited using the following DOI: 10.5281/zenodo.5175871.

\section{References and Notes}

(1) O'Neill, R. T.; Boulatov, R. Nat. Rev. Chem. 2021, 5, 148.

(2) Chen, Y.; Mellot, G.; van Luijk, D.; Creton, C.; Sijbesma, R. P. Chem. Soc. Rev. 2021, 50, 4100.

(3) Yuan, Y.; Yuan, W.; Chen, Y. Sci. China Mater. 2016, 59, 507.

(4) Göstl, R.; Clough, J. M.; Sijbesma, R. P. In Mechanochemistry in Materials Craig S. L.; Royal Society of Chemistry, London, 2017; 53.

(5) Traeger, H.; Kiebala, D. J.; Weder, C.; Schrettl, S. Macromol. Rapid Commun. 2021, 42, 2000573.

(6) Davis, D. A.; Hamilton, A.; Yang, J.; Cremar, L. D.; Van Gough, D.; Potisek, S. L.; Ong, M. T.; Braun, P. V.; Martínez, T. J.; White, S. R.; Moore, J. S.; Sottos, N. R. Nature 2009, 459, 68.

(7) Li, J.; Nagamani, C.; Moore, J. S. Acc. Chem. Res. 2015, 48, 2181.

(8) Chen, Y.; Spiering, A. J. H.; Karthikeyan, S.; Peters, G. W. M.; Meijer, E. W.; Sijbesma, R. P. Nat. Chem. 2012, 4, 559.

(9) Ducrot, E.; Chen, Y.; Bulters, M.; Sijbesma, R. P.; Creton, C. Science 2014, 344, 186.

(10) Imato, K.; Irie, A.; Kosuge, T.; Ohishi, T.; Nishihara, M.; Takahara, A.; Otsuka, H. Angew. Chem. Int. Ed. 2015, 54, 6168.

(11) Kosuge, T.; Zhu, X.; Lau, V. M.; Aoki, D.; Martinez, T. J.; Moore, J. S.; Otsuka, H. J. Am. Chem. Soc. 2019, 141, 1898.

(12) Kato, S.; Furukawa, S.; Aoki, D.; Goseki, R.; Oikawa, K.; Tsuchiya, K.; Shimada, N.; Maruyama, A.; Numata, K.; Otsuka, H. Nat. Commun. 2021, 12, 126.

(13) Löwe, C.; Weder, C. Adv. Mater. 2002, 14, 1625.

(14) Traeger, H.; Sagara, Y.; Kiebala, D. J.; Schrettl, S.; Weder, C. Angew. Chem. Int. Ed. 2021, 60, 16191.

(15) Sagara, Y.; Traeger, H.; Li, J.; Okado, Y.; Schrettl, S.; Tamaoki, N.; Weder, C. J. Am. Chem. Soc. 2021, 143, 5519.

(16) Konda, S. S. M.; Brantley, J. N.; Varghese, B. T.; Wiggins, K. M.; Bielawski, C. W.; Makarov, D. E. J. Am. Chem. Soc. 2013, 135, 12722.

(17) Li, J.; Shiraki, T.; Hu, B.; Wright, R. A. E.; Zhao, B.; Moore, J. S. J. Am. Chem. Soc. 2014, 136, 15925.

(18) Noh, J.; Peterson, G. I.; Choi, T.-L. Angew. Chem. Int. Ed. 2021, 60, 18651.

(19) Göstl, R.; Sijbesma, R. P. Chem. Sci. 2016, 7, 370.

(20) Yildiz, D.; Baumann, C.; Mikosch, A.; Kuehne, A. J. C.; Herrmann, A.; Göstl, R. Angew. Chem. Int. Ed. 2019, 58, 12919.
(21) Baumann, C.; Stratigaki, M.; Centeno, S. P.; Göstl, R. Angew. Chem. Int. Ed. 2021, 60, 13287.

(22) Izak-Nau, E.; Demco, D. E.; Braun, S.; Baumann, C.; Pich, A.; Göstl, R. ACS Appl. Polym. Mater. 2020, 2, 1682.

(23) Willis-Fox, N.; Rognin, E.; Baumann, C.; Aljohani, T. A.; Göstl, R.; Daly, R. Adv. Funct. Mater. 2020, 30, 2002372.

(24) Stratigaki, M.; Baumann, C.; van Breemen, L. C. A.; Heuts, J. P. A.; Sijbesma, R. P.; Göstl, R. Polym. Chem. 2020, 11, 358.

(25) Slootman, J.; Waltz, V.; Yeh, C. J.; Baumann, C.; Göstl, R.; Comtet, J.; Creton, C. Phys. Rev. X 2020, 10, 041045.

(26) Morelle, X. P.; Sanoja, G. E.; Castagnet, S.; Creton, C. Soft Matter 2021, 17, 4266.

(27) Dubach, F. F. C.; Ellenbroek, W. G.; Storm, C. J. Polym. Sci. 2021, 59, 1188.

(28) Daniele, M. A.; Bandera, Y. P.; Foulger, S. H. Photochem. Photobiol. 2012, 88, 129.

(29) Synthesis of OFP diol 2 Mechanophore precursor 1 (549 mg, $1.6 \mathrm{mmol}, 1.00$ equiv) and 3-azido-1-propanol (155 $\mu \mathrm{L}, 1.68$ mmol, 1.05 equiv) were dissolved in a mixture of THF $(20 \mathrm{~mL})$ and water $(6 \mathrm{~mL})$. Sodium l-ascorbate $(317 \mathrm{mg}, 1.6 \mathrm{mmol}, 1.00$ equiv) was added, followed by $\mathrm{Cu}^{\mathrm{II}} \mathrm{SO}_{4} \cdot 5 \mathrm{H}_{2} \mathrm{O}(40 \mathrm{mg}, 0.16 \mathrm{mmol}$, 0.100 equiv). The heterogeneous mixture was stirred vigorously at $\mathrm{rt}$ overnight and was afterwards diluted with water $(50 \mathrm{~mL})$. THF was removed in vacuo, and the white precipitate was cooled in an ice bath before collection by filtration. After washing the precipitate with cold water $(2$ ( $25 \mathrm{~mL})$, it was dried in vacuo to yield the triazole mechanophore diol $\mathbf{2}$ (70\% yield) as white solid. ${ }^{1} \mathrm{H}$ NMR $\left(400 \mathrm{MHz}\right.$, DMSO- $\left.d_{6}\right): \delta=8.54(\mathrm{~s}, 1 \mathrm{H})$, $7.52(\mathrm{dd}, J=7.4,1.2 \mathrm{~Hz}, 1 \mathrm{H}), 7.41(\mathrm{dd}, J=6.8,1.9 \mathrm{~Hz}, 1 \mathrm{H}), 7.30$ $(\mathrm{dd}, J=6.5,2.0 \mathrm{~Hz}, 1 \mathrm{H}), 7.18(\mathrm{qt}, J=5.6,2.6 \mathrm{~Hz}, 3 \mathrm{H}), 7.04(\mathrm{td}$, $J=7.6,1.3 \mathrm{~Hz}, 1 \mathrm{H}), 6.26(\mathrm{~d}, J=7.6 \mathrm{~Hz}, 1 \mathrm{H}), 4.85(\mathrm{~d}, J=3.1 \mathrm{~Hz}$, $1 \mathrm{H}), 4.75(\mathrm{t}, J=5.1 \mathrm{~Hz}, 1 \mathrm{H}), 4.63(\mathrm{t}, J=7.0 \mathrm{~Hz}, 2 \mathrm{H}), 4.59(\mathrm{t}, J=$ $5.9 \mathrm{~Hz}, 1 \mathrm{H}), 3.90(\mathrm{~d}, J=8.3 \mathrm{~Hz}, 1 \mathrm{H}), 3.53(\mathrm{dt}, J=7.6,6.0 \mathrm{~Hz}$, $2 \mathrm{H}$ ), 3.38 (dd, $J=8.3,3.1 \mathrm{~Hz}, 1 \mathrm{H}$ ), 2.95 (ddt, $J=13.0,9.2,4.7$ $\mathrm{Hz}, 2 \mathrm{H}), 2.64-2.41(\mathrm{~m}, 2 \mathrm{H}), 2.12(\mathrm{p}, J=6.7 \mathrm{~Hz}, 2 \mathrm{H})$; see Figure S1. ${ }^{13} \mathrm{C}$ NMR $\left(101 \mathrm{MHz}\right.$, DMSO- $\left.d_{6}\right): \delta=175.94,174.94,144.29$, $143.10,141.00,139.27,138.42,126.58,126.56,126.17,126.15$, 125.93, 124.82, 124.30, 123.80, 123.67, 57.49, 56.34, 49.23, 48.09, 47.50, 46.76, 44.89, 33.10; see Figure S2. ESI ${ }^{+}$HRMS: $\mathrm{m} / z$ [MH$\left.{ }^{+}\right]$calcd: 445.1870; found: 445.1942; see Figure S3.

(30) Cravotto, G.; Gaudino, E. C.; Cintas, P. Chem. Soc. Rev. 2013, 42, 7521.

(31) Dawson, W. R.; Windsor, M. W. J. Phys. Chem. 1968, 72, 3251.

(32) Ast, S.; Fischer, T.; Müller, H.; Mickler, W.; Schwichtenberg, M.; Rurack, K.; Holdt, H.-J. Chem. Eur. J. 2013, 19, 2990.

(33) Stevenson, R.; De Bo, G. J. Am. Chem. Soc. 2017, 139, 16768.

(34) Sato, T.; Nalepa, D. E. J. Appl. Polym. Sci. 1978, 22, 865.

(35) Kryger, M. J.; Munaretto, A. M.; Moore, J. S. J. Am. Chem. Soc. 2011, 133, 18992.

(36) Stauch, T.; Dreuw, A. Chem. Sci. 2017, 8, 5567.

(37) Jacobs, M. J.; Schneider, G.; Blank, K. G. Angew. Chem. Int. Ed. 2016, 55, 2899. 